\title{
DESIGN \& FABRICATION OF HYBRID SYSTEM FOR ELECTRICAL INDUSTRY
}

\author{
N. B. Survase, Jaydip Ingale, Pradip Bolake, Rohit Rarab, and Prathamesh Ghanti
}

\begin{abstract}
Now days in industry, materials (which are available in raw material, finished parts, assembly parts etc.) are kept in a storeroom with stock and mix-up parts to each other which may be damage. So, secure tools, raw material, manufactured parts, and assembly parts of industry have stored in rotary storage system. This system is very useful for material storage in industrial application.Storage compartments rotateby using chain and sprocket mechanism.It is simple to operate with the employee to store the material in the system at the ground level.Each employee has a unique ID for store materialin compartments andretrieved material from compartments. Traditional systems have a major disadvantage of large space consumption and damaging material which is successfully eliminated with the use of a rotary storage system. Moreover, the latter provides the added benefits of flexible operation without the need of an attendant and added security and least chances of material damage. Since the model makes use of composite parts, it is easy to assemble and dismantle and is thus more convenient than the traditional storage systems. The idea is to storage and move materialwith no disturbance to the already stored materialin rotary storage system. Once the employee leaves the incorporated safety zone the system rotating to lift the stored material compartment away from the bottom to central position. This leaves an empty compartment available at the ground level for the next material to be stored in. The stored material iseasily retrieved by pushing the button for the relevant position number in whichmaterial is stored. This causes the required material compartment to rotate down to ground level ready for the employee of industry to enter the safety zone.
\end{abstract}

Index Terms —chain sprocket mechanism;

Reference to this paper should be made as follows:

N. B. Survase, Jaydip Ingale, Pradip Bolake, Rohit Rarab, and Prathamesh Ghanti (2020), "DESIGN \& FABRICATION OF HYBRID SYSTEM FOR ELECTRICAL INDUSTRY” Int. J. of Mechanical, Robotics and Production Engineering, Vol. 7, No. 1, pp. 17-25

\section{Biographical notes:}

N. B. Survase, Asst. Professor in Department of Mechanical Engineering, Universal college of engineering \& research, sasewadi, Pune, Maharastra, India-412205.

Jaydip Ingale, Pradip Bolake, Rohit Rarab, and Prathamesh Ghanti are scholars in Department of Mechanical Engineering, Universal college of engineering \& research, sasewadi,Pune, Maharastra, India-412205.

Published by: International Associations of Professionals and Technical Teachers (IAPAT) 


\section{INTRODUCTION}

It is simple to operate with the employee storing material in the system at the ground level. Once the employee leaves the incorporated safety zone the compartment is automatically stored material by the system rotating to lift the stored material compartment away from the bottom central position. This leaves an empty compartment available at the ground level for the next material to be stored in. The stored materials are easily retrieved by pushing the button for the relevant position number of the compartmentis material stored in [1,2]. This causes the required compartment to rotate down to ground level ready for the employee to enter the safety zone and receive material out of the system. Except all other systems use a large ground area, Rotary storage System is developed to utilize maximum vertical area in the available minimum ground area. It is quite successful when installed in minimum areas which are well established and are suffering with shortage of area for storing material in industry. Although the construction of this system seems to be easy, it will be par from understanding without the knowledge of materials, chains, sprockets, bearings, and machining operations, kinematic and dynamic mechanism $[3,4,5]$

The Rotary Storage System for material such as material stored in storeroom, tools and equipment stored in cupboard etc. have been implemented on a huge scale. But these systems have a major disadvantage of large space consumption and worst management of organization which is successfully eliminated with the use of a rotary storage system. Moreover, the latter provides the added benefits of flexible operation without the need of an attendant and added security and least chances of materials damage. Since the model makes use of composite parts, it is easy to assemble and dismantle and is thus more convenient than the traditional materialstoring systems. The rotary model is specifically designed to accommodate material separately with less space.The materials are safely store and retrieve uniformly and unique shaped items [6,7]

The structure can accommodate six compartments in the space and can even be customized to hold a greater number depending upon the requirements of the organization.Storage spaces cannot cope with the growth of the different type of the materials. The structure of the system is like a building. [8]. The basic structure of the rotary storage systemcan be described with the help of block diagram.

\section{CONTRACTION \& WORKING DETAIL}

\section{A. Conuction}

1. Chain and sprocket mechanism:

A sprocket is a toothed wheel that fits onto a shaft. It is prevented from rotating on the shaft by a key that fits into keyways in the sprocket and shaft.

A chain is used to connect two sprockets. One sprocket is the driver sprocket. The other sprocket is the driven sprocket. Motion and force can be transmitted via the chain from one sprocket to another, therefore from one shaft to another. Chains that are used to transmit motion and force from one sprocket to another are called power transmission chains. An advantage of chain drives over most belt drives is that the chain cannot slip on the sprocket, so the chain and sprocket provides a positive, nonslip drive, i.e. the chain cannot slip on the sprocket because the sprocket teeth prevent the chain from slipping. 

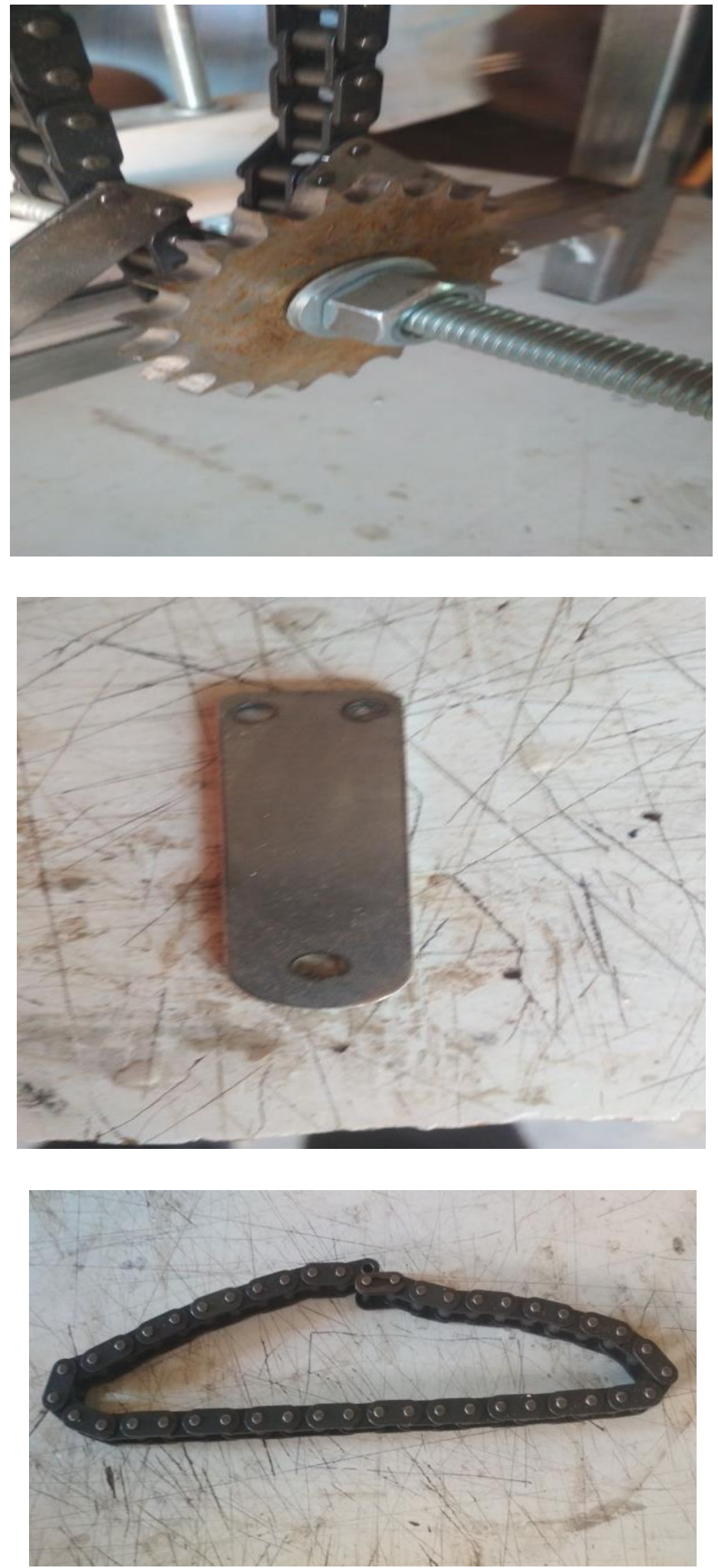

Fig 1 chain sprocket

1. Frame 


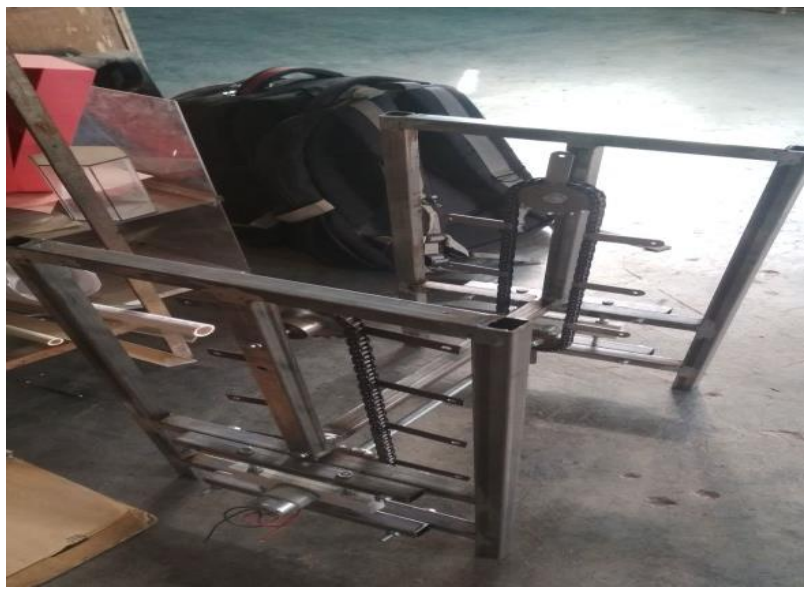

\section{Linear control system}

It consist of Control unit, Aurdino controller, RFID\& tag, IR sensors

The linear control system controls the relay which directly has control on the motor. The compartment movement of storing is dependent on the movement of the motor shaft. This movement can be clockwise as well as anticlockwise in both the directions according to the users' requirement. Not only the relay operation but also the Radio Frequency Identification (RFID) controls the users' details and sensors i.e. InfraRed Sensors are usedfor getting the details of the compartments,i.e., whether it is occupied or not. All these systems are controlled by the microcontroller.

\section{InfraRed (IR) Sensor:}

Theinfrared sensor allowsdetecting an object's distance.

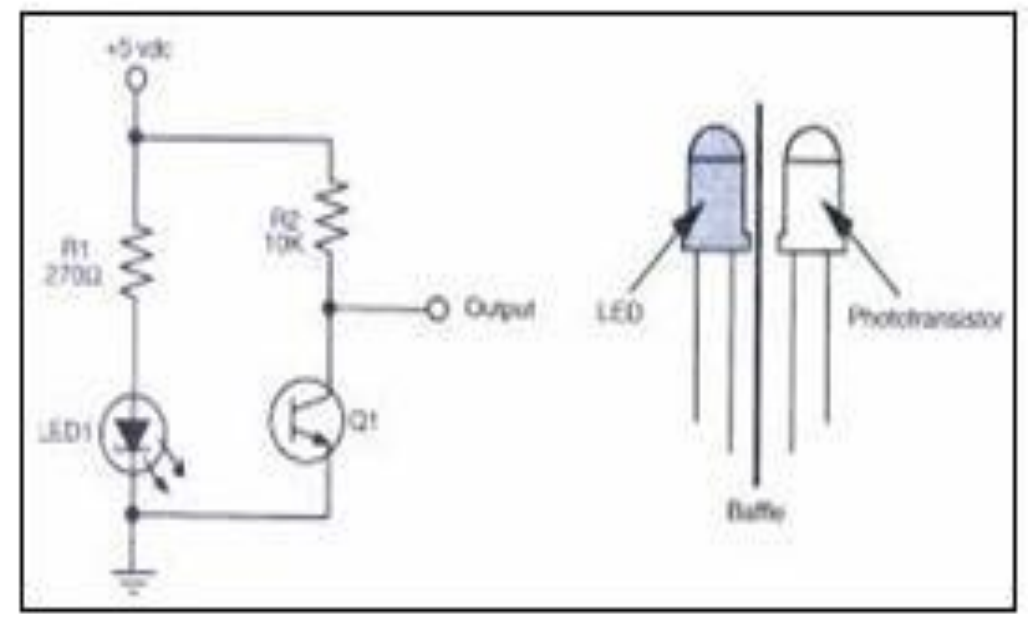

Fig.2: Infrared Sensor

Every compartment is fitted with a Light Emitting Diode (LED) and an IR sensor at the opposite ends on the inner side. This combination is used to check the status of the compartment, i.e., whether or not it is occupied.

4. RFID Tag/Reader: 
RFID is an abbreviation for Radio Frequency Identification. An RFID system consists of two parts .i.e., a reader, and one or more transponders, which are also known as tags. RFID systems have evolved from barcode labels as a means to automatically identify and track products as well as people. In the rotary storage system, the user is assigned a unique ID corresponding to the specific compartment. This helps in quick identification and movement of the same.

\section{Microcontroller}

The IC AT89S51is a low-power, high-performance CMOS 8- bit microcontroller and has 4K bytes of in-system programmable flash memory. This chip is manufactured using Atmel's high-density non-volatile memory technology and it is compatible with the industry- standard 80C51 instruction set and pin out. The on-chip flash memory allows the program memory to be reprogrammed insystem or by a conventional non-volatile memory programmer. Microcontroller 89S51 is preferred over $89 \mathrm{C} 51$ in this project due to the fact that the former requires $5 \mathrm{~V}$ for its operation whereas the latter needs to be supplied with $12 \mathrm{~V}$.

\section{Relay Driver}

There are 8 NPN Darlington pairs in this family of arrays and are ideally suited for interfacing between low logic level digital circuitry as well as the higher current or voltage requirements of relays, printer hammers or other similar loads for a broad range of applications in computers, industries and consumer applications. It features open-collector outputs and free-wheeling clamp diodes for transient suppression

\section{A. Block diagram}

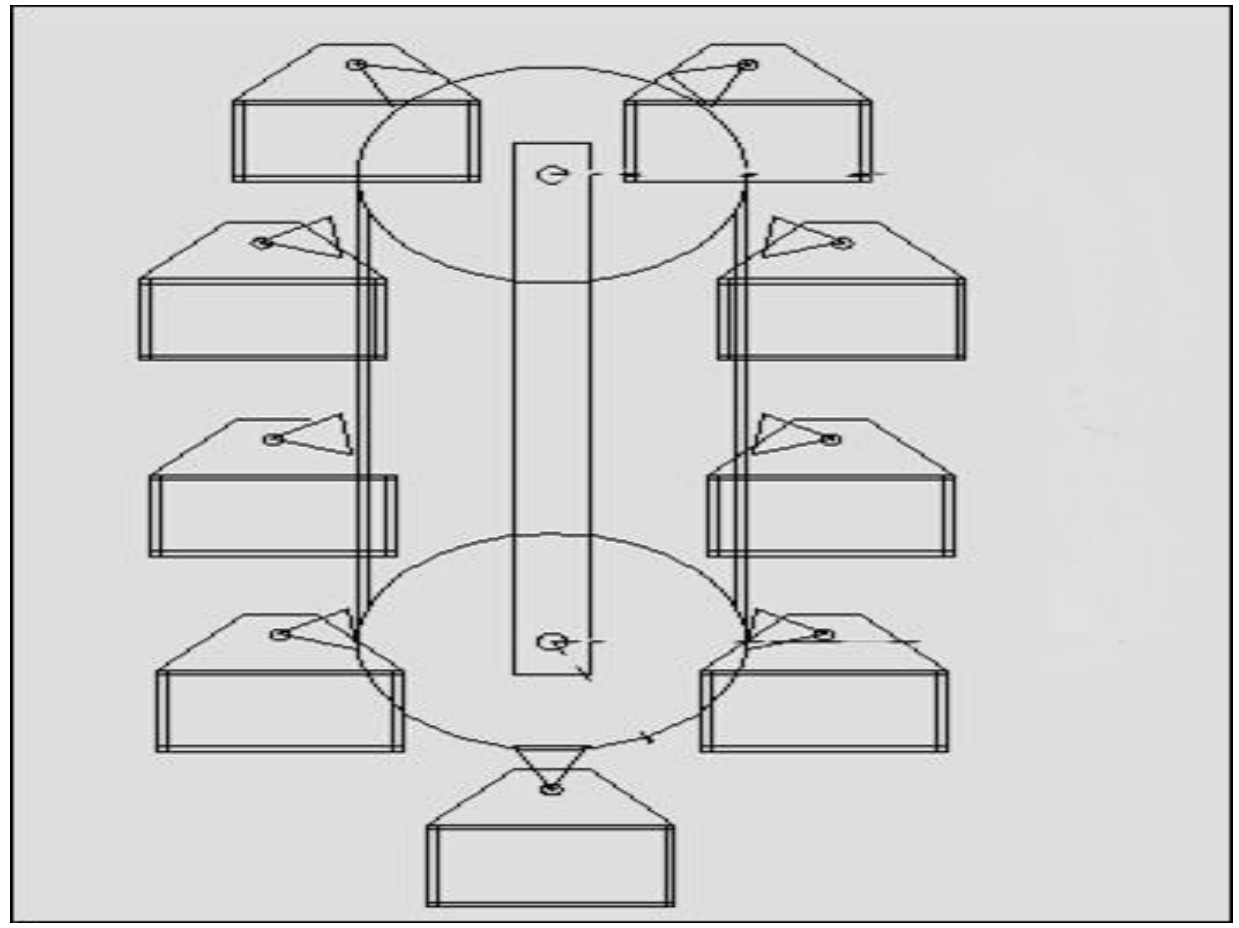

Fig 3. Rotary material system 


\section{CAD MODEL}

We prepare the cad model in CATIA software by creating each part one by one \& the by assembly module.

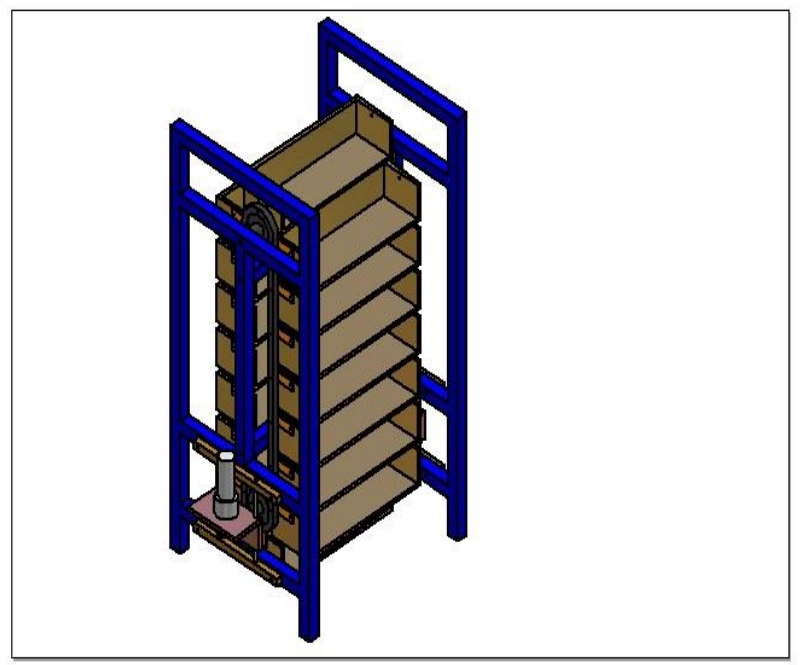

Fig. 4 CAD model

\section{Calculations}

1. Design calculations of chain drive

A chain drive consists of an endless chain wrapped around two sprockets as shown in Fig. 1. A chain can be defined as a series of links connected by pin joints. The sprocket is a toothed wheel with a special profile for the teeth. The chain drive is intermediate between belt and gear drives. It has some features of belt drives and some of gear drives.

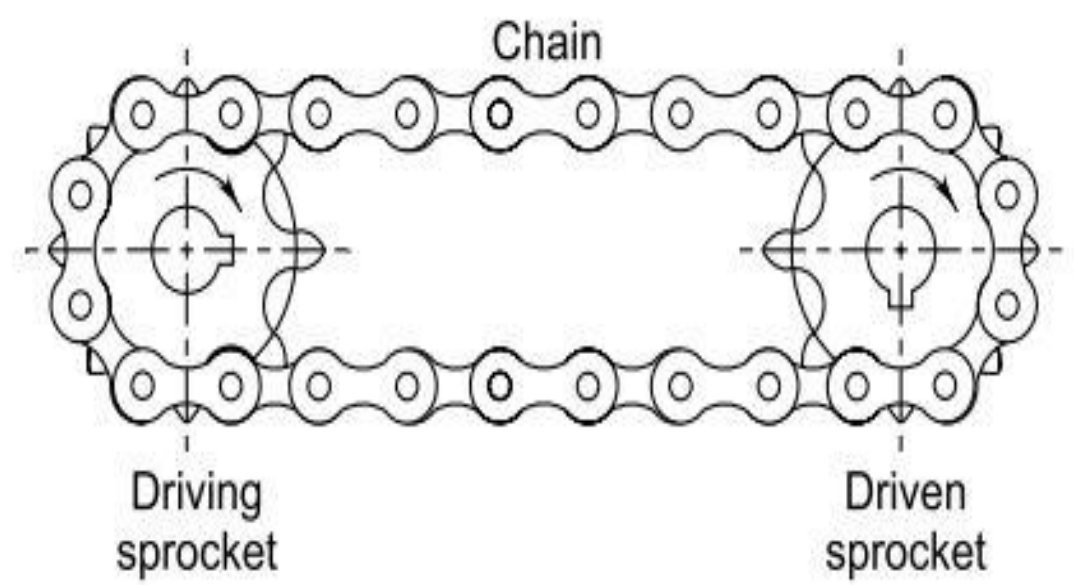

Fig 5 chain drive

*We required power transmitted for the further calculations POWER (P) 


$$
\begin{gathered}
\mathrm{P}=\frac{2 \pi n \mathrm{~T}}{60} \\
\mathrm{P}=\frac{2 \pi * 100 * 98.06}{60} \\
\mathrm{P}=1026.63 \mathrm{~W}
\end{gathered}
$$

KW Rating of Chain

$\underline{\text { (power to be transmitted)*Ks }}$

$$
=\frac{(1026.63) * 1.0}{1.18 * 1.18}
$$

Power rating $=737.31 \mathrm{~W}=.737 \mathrm{KW}$

Nearest value for $100 \mathrm{rpm}$ in table 14.2 is 0.64

For $100 \mathrm{rpm} \&$ Power 0.64KW

From table 1 Power rating of simple roller chain

The Power rating at $08 \mathrm{~B}$ is $100 \mathrm{rpm} \& .64 \mathrm{KW}$ power

Therefore chain number 08B is selected.

From table 2

For chain number 08B

*Dimensions

Pitch (P)

Roller diameter (d1)

$$
\begin{aligned}
\mathrm{P}=12.70 \mathrm{~mm} \\
\mathrm{~d} 1=8.51 \mathrm{~mm} \\
\mathrm{~b} 1=7.75 \mathrm{~mm} \\
\mathrm{Pt}=13.92 \mathrm{~mm}
\end{aligned}
$$

Transverse Pitch $(\mathrm{Pt})$

1. Shaft design

Material of shaft is Mild steel

Permissible shear stress

$$
\begin{gathered}
\tau=\frac{\text { Sys }}{\mathrm{FS}}=\frac{0.5 * \text { Syt }}{\mathrm{FS}} \\
\tau=\frac{0.5 * 150}{2} \\
\tau=37.5 \mathrm{~N} / \mathrm{mm} 2
\end{gathered}
$$

Torque supplied to the shaft is given by

$$
\begin{gathered}
\mathrm{Mt}=(\mathrm{T} 1-\mathrm{T} 2) * 85 / 2 \\
=(1743.05-672.82) * 85 / 2 \\
=90970 \mathrm{~N} \cdot \mathrm{mm}
\end{gathered}
$$

Shaft diameter,

$$
\begin{gathered}
2 \tau_{\max }=\frac{16}{\pi d^{3}} \sqrt{\left(\mathrm{M}_{\mathrm{b}}\right)^{2}+\left(\mathrm{M}_{\mathrm{t}}\right)^{2}} \\
2 * 37.5=\frac{16}{\pi d^{3}} * \sqrt{(89.350 .19)^{2}+90.97^{\wedge} 2} \\
\mathrm{D}=8.66 \mathrm{~mm}
\end{gathered}
$$

Taking safe value diameter of shaft is $10 \mathrm{~mm}$ 


\section{Conclusion}

We have designed and all the composite parts in it have been manufactured and assembled. The mechanical model has been designed and the software as well as the control circuit has been implemented successfully. It demonstrates the working of the planned rotary parking system. The size and number of trolleys can be customized according to the needs and capacity of the organization or garage space availability. 


\section{REFERENCES}

[1] Abdul halim bin hadzir, "Development of automated storage and retrieval system (as/rs) prototype"

[2] GAPS Guidelines carousel storage A Publication of Global Asset Protection Services

[3] Chandni Patel, Monalisa Swami, Priya Saxena, Sejal Shah "Rotary Automated Car Parking System". International Journal of Engineering Science and Innovative Technology (IJESIT) Volume 4, Issue 2, March 2015

[4] Rahul J.Kolekar, S.S.Gawade, "Design and development of lift for an automatic car parking system" [4] International Journal of Emerging Technology and Advanced Engineering Website: www.ijetae.com (ISSN 2250-2459, ISO 9001:2008 Certified Journal, Volume 5, Issue 4, April 2015)

[5] M Childs, "Parking Spaces; A Design, Implementation and Use Manual for Architects Planners and Engineers" McGraw-Hill, 2009.

[6] D Y Park, "Vertical Rotary Parking" http://www. freepatentsonline.com/y2004/0156699.html (accessed on 11 November, 2010).

[7] M.A.R. Sarkar, A.A. Rokoni, M.O. Reza, M.F. Ismail, "Smart Parking system with image processing facility", I.J. Intelligent Systems and Applications, 2012, vol. 3, pp. 41-47.

[8] International Symposium on V.W. S. Tang, Y. Zheng, Sensor Networks," Proceedings of the 1st and J. Cao, "An Intelligent Car Park Management System based on Wireless Pervasive Computing and Applications, pp. 65-70, Aug 2006.

[9] S. Manivannan, Sarathy Kannan Gopalakrishnan, S.P. Kumaresh Babu, Srinivasan Sundarrajan, "Effect of cerium addition on corrosion behavior of AZ61 + XCe alloy under salt spray test" Alexandria Engineering Journal (2016)55, 663-671

[10]F.F. Chen, M. Breedon, E.D. Sapper, W. Ganther, D. Lau, I. Cole, "A microclimate model to simulate neutral salt spray testing for corrosion inhibitor evaluation and functional coating development" Progress in Organic Coatings 111 (2017) 327-335. 